Check for updates

Cite this: Metallomics, 2018, 10, 854

Received 9th March 2018, Accepted 6th June 2018

DOI: $10.1039 / c 8 m t 00052 b$

rsc.li/metallomics

\section{Systems impact of zinc chelation by the epipolythiodioxopiperazine dithiol gliotoxin in Aspergillus fumigatus: a new direction in natural product functionality $\dagger$}

\author{
Aliabbas A. Saleh, (D) a Gary W. Jones, (D) ab Frances C. Tinley, ${ }^{a}$ Stephen F. Delaney, ${ }^{a}$ \\ Sahar H. Alabbadi, (D) ${ }^{a}$ Keith Fenlon, ${ }^{a}$ Sean Doyle (D)*a and Rebecca A. Owens (D) *a
}

\begin{abstract}
The non-ribosomal peptide gliotoxin, which autoinduces its own biosynthesis, has potent anti-fungal activity, especially in the combined absence of the gliotoxin oxidoreductase GliT and bis-thiomethyltransferase GtmA. Dithiol gliotoxin (DTG) is a substrate for both of these enzymes. Herein we demonstrate that DTG chelates $\mathrm{Zn}^{2+}\left(\mathrm{m} / \mathrm{z}\right.$ 424.94), rapidly chelates $\mathrm{Zn}^{2+}$ from $\mathrm{Zn}\left(4\right.$-(2-pyridylazo)-resorcinol) $\left(\mathrm{Zn}(\mathrm{PAR})_{2}\right)$ and also inhibits a $\mathrm{Zn}^{2+}$-dependent alkaline phosphatase (AP). $\mathrm{Zn}^{2+}$ addition rescues AP function following DTG-associated inhibition, and pre-incubation of DTG with $\mathrm{Zn}^{2+}$ completely protects AP activity. $\mathrm{Zn}^{2+}$ $(1-50 \mu \mathrm{M})$ also significantly relieves the potent gliotoxin-mediated inhibition of Aspergillus fumigatus $\Delta$ gliT:: $\Delta$ gtmA $(p<0.05)$, which infers in vivo dithiol gliotoxin-mediated sequestration of free $\mathrm{Zn}^{2+}$ or chelation from intracellular metalloenzymes as inhibitory mechanisms. Quantitative proteomic analysis revealed that excess $Z^{2+}$ alters the effect of gliotoxin on A. fumigatus $\Delta g l i T$, with differential abundance of secondary metabolism-associated proteins in the combinatorial condition. GtmA abundance increased 18.8 fold upon co-addition of gliotoxin and $\mathrm{Zn}^{2+}$ compared to gliotoxin alone, possibly to compensate for disruption to GtmA activity, as seen in in vitro assays. Furthermore, DTG effected significant in vitro aggregation of a number of protein classes, including $\mathrm{Zn}^{2+}$-dependent enzymes, while proteins were protected from aggregation by pre-incubating DTG with $\mathrm{Zn}^{2+}$. We conclude that DTG can act in vivo as a $\mathrm{Zn}^{2+}$ chelator, which can significantly impede A. fumigatus growth in the absence of GliT and GtmA.
\end{abstract}

Significance to metallomics

Dithiol gliotoxin is a near-terminal biosynthetic intermediate from the gliotoxin biosynthetic pathway in the human pathogen Aspergillus fumigatus. Chemically reduced gliotoxin, dithiol gliotoxin (DTG), is revealed as a biological zinc chelator, and conversely, zinc can relieve the hitherto cryptic fungal autotoxicity of DTG. There is a systems-wide impact of zinc chelation by DTG on the fungal proteome, and we suggest it is DTG, as opposed to gliotoxin, which chelates zinc from metalloproteins. Since gliotoxin can be sequestered by both fungi and bacteria, our findings infer a new avenue to interfere with, and exploit, cellular zinc homeostasis in microorganisms.

\section{Introduction}

Gliotoxin and holomycin are microbial natural products, which are produced by fungal and bacterial spp., respectively (Fig. 1). ${ }^{1-3}$ Both are low molecular mass metabolites, and each contains a

\footnotetext{
${ }^{a}$ Department of Biology, Maynooth University, Co. Kildare, Ireland. E-mail: sean.doyle@mu.ie, rebecca.owens@mu.ie; Tel: +353-1-708-3858, +353-1-708-3839

${ }^{b}$ Centre for Biomedical Research, School of Clinical and Applied Sciences, Leeds-Beckett University, Leeds LS1 3HE, UK

$\dagger$ Electronic supplementary information (ESI) available. See DOI: 10.1039/c8mt00052b
}

disulphide bridge formed by the action of oxidoreductases, namely GliT and HlmI, on the respective dithiol precursor (Fig. 1). ${ }^{4-6}$ Disulphide bridge formation is essential for microbial self-protection against these reactive dithiol intermediates, and is a pre-requisite for the Major Facilitator Superfamily transporter GliA-mediated secretion of gliotoxin by Aspergillus fumigatus. ${ }^{5-8}$ Both metabolites are also present as bis-thiomethylated forms, and gliotoxin bis-thiomethyltransferase GtmA converts dithiol gliotoxin (DTG) to bis-dethiobis(methylthio)gliotoxin (BmGT) in A. fumigatus, whereas the origin of the cognate activity against dithiol holomycin in Streptomyces clavuligeris is unknown (Fig. 1). ${ }^{9,10}$ Bernardo et al. have shown that upon uptake by eukaryotic cells, 


$$
\text { A. }
$$

Dithiol Gliotoxin

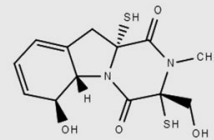

GliT /

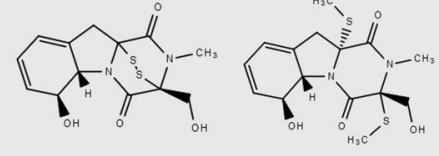

Gliotoxin
B.

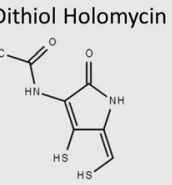

$\mathrm{HIml}$
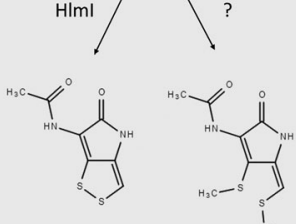

Holomycin Holomycin

Fig. 1 Unrelated microbial dithiol-containing compounds undergo equivalent biotransformations, and appear to be co-substrates for two enzyme functionalities. (A) In Aspergillus fumigatus, DTG is either oxidised to gliotoxin via gliotoxin oxidoreductase GliT or bis-thiomethylated by gliotoxin bis-thiomethyltransferase GtmA. (B) In Streptomyces clavuligeris, dithiol holomycin undergoes oxidoreductase $\mathrm{HIml}$-mediated conversion to holomycin. The enzyme which catalyses $S, S^{\prime}$-dimethyl holomycin formation remains to be identified.

gliotoxin is chemically reduced to the dithiol form by intracellular glutathione $(\mathrm{GSH}){ }^{11}$ Carberry et al. revealed significantly elevated intracellular GSH in gliotoxin-sensitive A. fumigatus $\Delta g l i T$ and that Saccharomyces cerevisiae $\Delta g s h 1$, deficient in intracellular GSH, was resistant to exogenous gliotoxin. ${ }^{12}$ The epipolythiodioxopiperazine (ETP) gliotoxin autoinduces its own biosynthesis by activating gli biosynthetic gene cluster expression, and BmGT formation has been shown to result in gli cluster attenuation in A. fumigatus, which results in the repression of gliotoxin biosynthesis. ${ }^{9,13,14}$ Methylation of dithiol holomycin has been proposed as a back-up plan for self-protection, and Dolan et al. revealed that A. fumigatus $\Delta g l i T:$ : $\Delta$ tmA is significantly more sensitive to exogenous gliotoxin than a gliT-deficient mutant. ${ }^{15}$ This suggests that the combined absence of both self-protection and negative regulation of DTG biosynthesis (or its intracellular presence) results in potent growth retardation - the precise cause of which is unknown. ${ }^{10,15}$

Gliotoxin, other ETPs and dithiolopyrrolones have been shown to inhibit the activity of many enzymes, and functionality of specific proteins. ${ }^{16-21}$ Several studies have demonstrated that the disulphide moiety of gliotoxin is responsible for most of the associated bioactivity of this molecule, whereas the $S$-methylated BmGT molecule is relatively inactive. ${ }^{17,22}$ In general, reactivity of gliotoxin towards protein thiols, damage from redox cycling, and $\mathrm{Zn}^{2+}$ ejection have been proposed as the respective mechanisms whereby protein functionality is altered. Interestingly, addition of the reducing agent, L-dithiothreitol (DTT), significantly augmented the inhibitory activity of gliotoxin towards farnesyltransferase, and either DTT or GSH augmented gliotoxin-mediated inhibition of equine alcohol dehydrogenase. ${ }^{16,17}$ Notably, neither of the aforementioned studies posited DTG-mediated $\mathrm{Zn}^{2+}$ chelation from either $\mathrm{Zn}^{2+}$-dependent enzyme as the inhibitory mechanism.
In combination, these observations led us to hypothesise that, acting as a potent $\mathrm{Zn}^{2+}$ chelator, DTG (and not gliotoxin), could exhibit an equivalent mechanism of action towards $\mathrm{Zn}^{2+}$-dependent enzyme systems. Moreover, DTG interference with $\mathrm{Zn}^{2+}$ availability or $\mathrm{Zn}^{2+}$-dependent enzyme activity in A. fumigatus $\Delta g l i T:: \Delta g t m A$ could be the basis for observed and extreme growth retardation. ${ }^{15}$ However, it is also essential to consider a mechanistic reciprocity between DTG and $\mathrm{Zn}^{2+}$. Consequently, while DTG may chelate the cation and impede $\mathrm{Zn}^{2+}$-mediated enzyme activities, excess or available metal ion may provide protection against intracellular DTG. Indeed, zinc salts have been successfully used to reverse ovine and bovine facial eczema associated with exposure to fungal ETPs such as sporidesmin A, a related disulphide-containing metabolite secreted by Pithomyces chartarum. ${ }^{23}$ It is postulated that $\mathrm{Zn}^{2+}$ chelates formed with sporidesmin A may attenuate its unwanted biological effects. Interestingly, Woodcock et al. presented mass spectrometric evidence of $\mathrm{Zn}^{2+}$ [sporidesmin] chelates, and noted that $\mathrm{Zn}^{2+}$ [gliotoxin] chelates, following $\mathrm{NaBH}_{4}$-mediated reduction, also existed, namely $[2 \text { gliotoxin }+\mathrm{Zn}]^{2-},[2$ gliotoxin + $\mathrm{Zn}+\mathrm{Na}]^{-}$and [gliotoxin $\left.+\mathrm{ZnCl}\right]^{-}\left(\mathrm{m} / z\right.$ 427). ${ }^{24}$ These authors speculated that that mono-ligands with halide coordination were the preferable complex form, however corresponding mass spectra and fragmentation patterns were not presented.

The ZafA transcriptional regulator, which can induce expression of the $\mathrm{Zn}^{2+}$ transporters $z r f A, z r f B$ and $z r f C$, regulates zinc homeostasis in A. fumigatus and is essential for virulence. ${ }^{25-28}$ $\mathrm{ZrfC}$ is the key essential transporter which effects $\mathrm{Zn}^{2+}$ acquisition by A. fumigatus, while ZrfA and ZrfB play accessory and nonessential roles. ${ }^{26}$ Interestingly, transporter ZrfB (AFUA_2G03860) was found to be significantly increased in abundance $\left(\log _{2}\right.$-fold increase: 1.31) in long-term A. fumigatus $\Delta$ gtmA cultures, which suggests interplay between dysregulated gliotoxin biosynthesis and $\mathrm{Zn}^{2+}$ homeostasis. ${ }^{29}$

Herein, for the first time we reveal DTG as a $\mathrm{Zn}^{2+}$ chelator which can specifically and significantly inhibit $\mathrm{Zn}^{2+}$-dependent metalloenzyme activity. Moreover, we demonstrate that $\mathrm{Zn}^{2+}$ significantly reverses the inhibitory effects of gliotoxin on A. fumigatus $\Delta g l i T:: \Delta g t m A$, which implicates intracellular $\mathrm{Zn}^{2+}$ chelation as a potential growth inhibitory strategy against this pathogen. ${ }^{15}$ Significant proteomic remodelling in A. fumigatus $\Delta$ gliT in response to gliotoxin versus $\mathrm{Zn}^{2+}$ /gliotoxin exposure further illuminates a hitherto unanticipated in vivo interaction between DTG and $\mathrm{Zn}^{2+}$.

\section{Methods}

\section{High resolution mass spectrometry detection of gliotoxin complexed to $\mathrm{Zn}^{2+}$}

Tris(2-carboxyethyl)phosphine hydrochloride (TCEP)-reduced gliotoxin (DTG; $300 \mu \mathrm{M}$ final) was mixed with $\mathrm{ZnSO}_{4} \cdot 7 \mathrm{H}_{2} \mathrm{O}$ in the presence of formic acid $(0.1 \%(\mathrm{v} / \mathrm{v}))$ to achieve $0.5,1$ and 3-fold molar equivalents of $\mathrm{Zn}^{2+}$ to DTG. Samples were passed through $0.22 \mu \mathrm{m}$ spin filters and directly injected onto a Thermo Q-Exactive Mass spectrometer $\left(5 \mu \mathrm{min}^{-1}\right)$. Assessment of DTG-Zn ${ }^{2+}$ 
complex formation was evaluated by both positive and negative ESI mode with full MS scan (50-2000.00). The following settings were used in the analysis: spray voltage (negative mode: $3.6 \mathrm{kV}$, positive mode $4 \mathrm{kV}$ ), capillary temperature $320{ }^{\circ} \mathrm{C}$.

\section{Assessment of in vitro $\mathrm{Zn}^{2+}$ chelation by DTG}

Zinc binding assays were performed as described in Chan et al. with some modifications. ${ }^{30}$ Titrations were carried out in PBS pH 7.4 (1 ml final volume). 4-(2-Pyridylazo)-resorcinol (PAR) $(80 \mu \mathrm{l} ; 1.5 \mathrm{mM})$ was added with $60 \mu \mathrm{l} 1 \mathrm{mM} \mathrm{ZnSO}_{4}$, per ml to yield final ratio of $2: 1$ (PAR: $\mathrm{Zn}^{2+}$ ). DTG (2.5 mM in methanol) was prepared by 60 min pre-incubation with $12.5 \mathrm{mM}$ TCEP in $100 \mu \mathrm{l}$ final volume and was then added in increasing concentration to yield 1, 2, 3, 4 and 5 molar equivalents of DTG to $\mathrm{Zn}(\mathrm{PAR})_{2}$ (final concentrations: $60 \mu \mathrm{M} \mathrm{Zn}{ }^{2+}, 120 \mu \mathrm{M}$ PAR, 60-300 $\mu \mathrm{M}$ DTG). $12.5 \mathrm{mM}$ TCEP in methanol and oxidised gliotoxin (2.5 $\mathrm{mM})$ were used as negative controls. After addition of all components, absorbance spectra were recorded between 200-800 nm.

\section{Alkaline phosphatase (AP) and GtmA enzyme assays}

$\mathrm{Zn}^{2+}$-Dependent AP from bovine intestinal mucosa (AP; $1.44 \mathrm{U} \mathrm{ml}^{-1}$ (Sigma-Aldrich)) in PBS was pre-incubated with the following agents to determine the extent of enzyme inhibition: $5 \mathrm{mM}$ EDTA, $150 \mu \mathrm{M}$ gliotoxin (GT), 10-150 $\mu \mathrm{M}$ DTG (TCEP-reduced GT), $50 \mu \mathrm{M}$ TPEN ( $N, N, N^{\prime}, N^{\prime}$-tetrakis(2-pyridylmethyl)ethane-1,2-diamine), $50 \mu \mathrm{M}-5 \mathrm{mM}$ DTT, or $50 \mu \mathrm{M}-5 \mathrm{mM}$ GSH for $15 \mathrm{~min}$ in triplicate. Control or treated $\mathrm{AP}$ (50 $\mu \mathrm{l}$ per reaction) was added to $1 \mathrm{ml} p$-nitrophenol phosphate (pNPP) (5 mM; dissolved in PBS with $50 \mathrm{mM}$ glycine $\mathrm{pH}$ 9.5) and assayed in triplicate at $37{ }^{\circ} \mathrm{C}$ for $30 \mathrm{~min}$. Enzyme reactions were terminated by addition of $20 \mathrm{mM} \mathrm{NaOH}(5 \mathrm{ml})$. AP activity was determined by $p$-nitrophenol (pNP) detection at $405 \mathrm{~nm}$ following pNPP hydrolysis. The protective effect of preincubating DTG or TPEN with $\mathrm{Zn}^{2+}$ was also evaluated using this assay system. DTG $(50 \mu \mathrm{M})$ or TPEN $(50 \mu \mathrm{M})$ were pre-incubated with $\mathrm{Zn}^{2+}(25-100 \mu \mathrm{M})$ for 15 min prior to addition of AP enzyme and the rest of the assay was performed as before. To test the capacity of $\mathrm{Zn}^{2+}$ to rescue DTP-associated loss of AP activity, AP was pre-incubated with DTG $(50 \mu \mathrm{M})$ for $15 \mathrm{~min}$, followed by addition of $\mathrm{Zn}^{2+}(0.1-1 \mathrm{mM})$ for a further $15 \mathrm{~min}$, prior to addition of pNPP substrate.

GtmA activity was determined as described in Dolan et al. to evaluate the effect of $\mathrm{Zn}^{2+}$ (molar ratio 0.0001-10 $\mathrm{Zn}^{2+}$ : 1 DTG) on the formation of BmGT. ${ }^{15}$ Briefly, $S$-adenosylmethionine (SAM) $(1 \mu \mathrm{M}$ final) and TCEP-reduced gliotoxin $(250 \mu \mathrm{M}$ final $)$ were combined, along with PBS. $\mathrm{Zn}^{2+}$ was added at a range of concentrations $(0.025,0.25,2.5,25,125,250 \mu \mathrm{M}$ and $2.5 \mathrm{mM})$, representing a molar ratio ranging from 0.0001 to $10: 1 \mathrm{Zn}^{2+}$ : DTG. A control was also prepared with no $\mathrm{Zn}^{2+}$ added. GtmA $(0.5 \mu \mathrm{M})$ was added to the mixture followed by incubation at $37{ }^{\circ} \mathrm{C}$ for $5 \mathrm{~min}$. Reactions were stopped by protein precipitation using TCA (final 15\%) and incubation on ice for $20 \mathrm{~min}$. Clarified mixtures were analysed by RP-HPLC and absorbance monitored at $254 \mathrm{~nm}$ to determine the concentration of BmGT and monomethyl gliotoxin (MmGT).

\section{Assessment of the effect of $\mathrm{Zn}^{2+}$ on alkylation of DTG}

Iodoacetamide (IAA) was used as an alkylating agent to investigate the effect of $\mathrm{Zn}^{2+}$ on alkylation of DTG. IAA stock (50 mM) was prepared in $50 \mathrm{mM}$ ammonium bicarbonate. $3 \mathrm{mM}$ DTG was prepared by 60 min pre-incubation of gliotoxin with $12.5 \mathrm{mM}$ TCEP. DTG ( $0.3 \mathrm{mM}$ final) was mixed with $\mathrm{ZnSO}_{4}$ at a range of concentrations $(0.1,0.15,0.3,0.6,0.9 \mathrm{mM})$ to achieve molar equivalents of $\mathrm{Zn}^{2+}$ to DTG of $0.33,0.5,1,2$ and 3, respectively. IAA was subsequently added at a final concentration of $3 \mathrm{mM}$ (ratio IAA:DTG 10:1) and incubated in the dark for $20 \mathrm{~min}$. All reactions were carried out in methanol at $100 \mu \mathrm{l}$ final volume. Control samples were included to measure levels of DTG and alkylated gliotoxin formed in the absence of $\mathrm{Zn}^{2+}$. Reactions were evaluated by RP-HPLC. ${ }^{15}$

\section{A. fumigatus phenotypic assays}

A. fumigatus $\Delta g l i T$ and $\Delta g l i T:$ : $\Delta$ gtmA strains were grown on MEA agar for 5 days at $37^{\circ} \mathrm{C}$. After incubation, conidia were harvested with PBST and washed three times with PBS and resuspended in PBS. Conidia were counted using haemocytometer and stored at $4{ }^{\circ} \mathrm{C}$ for future use. Conidia were serially diluted to $10^{3} \mu \mathrm{l}^{-1}$ and $5 \mu \mathrm{l}$ was spotted on Czapek-Dox agar plates (permissive for endogenous gliotoxin biosynthesis $\left.{ }^{7}\right)$ containing gliotoxin ( 0 , 15 or $30 \mu \mathrm{M}$ ) and $\mathrm{Zn}^{2+}$, respectively. Plates were then incubated at $37{ }^{\circ} \mathrm{C}$ and growth monitored up to $96 \mathrm{~h}$ by measuring radial growth (mm) of each colony. Two-way ANOVA analysis was performed to determine the statistical significance between strains at different concentrations of gliotoxin and $\mathrm{Zn}^{2+}$.

\section{Extraction and measurement of extracellular and intracellular} gliotoxin

A. fumigatus wild-type and $\Delta g l i T:$ : $\Delta g t m A$ were grown in Sabourauddextrose media for $21 \mathrm{~h}$ and gliotoxin was subsequently added for $3 \mathrm{~h}$ at $15 \mu \mathrm{M}$ with and without $\mathrm{Zn}^{2+}(n=3$ biological replicates for all specimens). $\mathrm{Zn}^{2+}$ was added at $1 \mathrm{mM}$ final concentration. Supernatant samples were taken after 15, 30, 60, 120 and $180 \mathrm{~min}$ and were extracted using chloroform $(1: 1)$, as described. ${ }^{31}$ The organic extracts were subsequently dried down and resuspended in methanol and analysed for gliotoxin content using RP-HPLC with UV detection (Shimadzu), using polar C18 RP-HPLC column (Phenomenex polar C18 Luna Omega column $(150 \mathrm{~mm} \times$ $4.6 \mathrm{~mm}, 5 \mu \mathrm{m})$ ) at a flow rate of $1 \mathrm{ml} \mathrm{min}^{-1}$. A mobile phase of acetonitrile and water with $0.1 \%(\mathrm{v} / \mathrm{v})$ TFA was used under gradient conditions. A. fumigatus wild-type was also grown in Czapek-Dox media for $72 \mathrm{~h}$ (gliotoxin-producing conditions) in the presence of either low $(0.027 \mathrm{mM})$ or high $(0.5 \mathrm{mM}) \mathrm{Zn}^{2+}(n=3$ biological replicates for all specimens). Controls were included, with no $\mathrm{Zn}^{2+}$ added. Aliquots were taken every $24 \mathrm{~h}$ and organic extractions and RP-HPLC analyses were performed as outlined above. For intracellular gliotoxin recovery, mycelia collected after $3 \mathrm{~h}$ incubation were harvested and snap frozen in liquid $\mathrm{N}_{2}$. Intracellular gliotoxin was extracted as described previously for SAM, using a modified protocol. ${ }^{8}$ Briefly, mycelia were ground using liquid $\mathrm{N}_{2}$ with a mortar and pestle. $100 \mathrm{mg}$ mycelia were incubated with $0.1 \mathrm{~N} \mathrm{HCl}(250 \mu \mathrm{l})$ on ice for $1 \mathrm{~h}$ 
with intermittent vortexing. Protein was removed by addition of $100 \%$ TCA to achieve a final concentration of $15 \%(\mathrm{v} / \mathrm{v})$ TCA. After centrifugation at $16000 \times g$, supernatants were collected and then analysed by RP-HPLC.

Proteomic analysis of gliotoxin affects, with and without $\mathrm{Zn}^{2+}$, on A. fumigatus $\Delta$ gliT

A. fumigatus $\Delta g l i T$ was cultured ( $n=3 /$ condition) for $21 \mathrm{~h}$ in Sabouraud-dextrose media (SDM) followed by addition of gliotoxin $(15 \mu \mathrm{M})$ or methanol (control) with and without $\mathrm{ZnSO}_{4}$ ( $1 \mathrm{mM}$ ) addition for $3 \mathrm{~h}$. Mycelia were then harvested and snap frozen in liquid $\mathrm{N}_{2}$. Mycelia were lysed using buffer (100 mM Tris-HCl, $50 \mathrm{mM} \mathrm{NaCl,} 20 \mathrm{mM}$ EDTA, 10\% v/v glycerol. $1 \mathrm{mM}$ PMSF, $1 \mu \mathrm{g} \mathrm{ml} \mathrm{ml}^{-1}$ pepstatin $\mathrm{A}, \mathrm{pH}$ 7.5) with grinding and sonication, and clarified using centrifugation. ${ }^{8}$ The protein lysates were then subjected to precipitation using TCA/acetone and resuspended in $100 \mathrm{mM}$ Tris- $\mathrm{HCl}, 6 \mathrm{M}$ urea, $2 \mathrm{M}$ thiourea, $\mathrm{pH}$ 8.0. Samples were then reduced by DTT and followed by alkylation using IAA. This was followed by addition of sequencing grade trypsin combined with Protease Max surfactant for overnight digestion. Following sample clean-up using Millipore C18 ZipTips, all peptide mixtures were analysed via a Thermo-Fisher Q-Exactive mass spectrometer coupled to a Dionex RSLCnano. ${ }^{32}$ LC gradients ran from $4 \%$ to $35 \%$ ACN over $2 \mathrm{~h}$, and data were collected using a Top15 method for MS/MS scans. Comparative proteome abundance and data analysis was performed using MaxQuant software (v. 1.5.3.30), with PERSEUS used to organize data (v. 1.5.4.0). ${ }^{33,34}$ Proteins with significant changes in abundance ( $p<0.05$; fold change $\geq 2$ ) signified quantitative changes between the sample treatments. Qualitative differences were also noted, where proteins were not detected in one group and were present in at least 2 replicates from the comparator group. Functional analysis was carried out using FungiFun2 (https:// elbe.hki-jena.de/fungifun/fungifun.php). ${ }^{35}$

\section{In vitro DTG induced-protein aggregation assays}

Protein extracts were prepared from A. fumigatus mycelia from three biological replicates, previously cultured in SDM at $37^{\circ} \mathrm{C}$, for $24 \mathrm{~h}$ at $200 \mathrm{rpm}$. Mycelia were harvested by filtering through Miracloth, snap-frozen and ground in liquid $\mathrm{N}_{2}$ using a pestle and mortar. Lysis buffer (0.1 M Tris- $\mathrm{HCl}, 50 \mathrm{mM} \mathrm{NaCl}, 1 \mathrm{mM}$ PMSF pH 7.5; $400 \mu \mathrm{l}$ ) was added to ground mycelia $(200 \mathrm{mg})$ and lysed by sonication. Lysates were clarified by centrifugation at $12000 \mathrm{~g}, 4{ }^{\circ} \mathrm{C}$ for $10 \mathrm{~min}$ and this was repeated twice to remove insoluble material. Lysates were diluted to $1 \mathrm{mg} \mathrm{ml}^{-1}$ and subjected to the following treatments in triplicate: (a) control: methanol and TCEP were added as a solvent control; (b) DTG: TCEP-reduced gliotoxin was added to the protein extracts to a final concentration of $150 \mu \mathrm{M}$ and (c) DTG/ $\mathrm{Zn}^{2+}$ :TCEP-reduced gliotoxin was pre-mixed with $\mathrm{ZnSO}_{4} \cdot 7 \mathrm{H}_{2} \mathrm{O}$ at a $1: 3$ molar ratio. The mixture was added to the protein extracts in triplicate to achieve a final concentration of $150 \mu \mathrm{M}$ DTG and $450 \mu \mathrm{M} \mathrm{Zn}^{2+}$. All samples were incubated at $50{ }^{\circ} \mathrm{C}$ for $30 \mathrm{~min}$ prior to addition of solubilisation buffer and analysis by SDS-PAGE. Protein aggregates were observed as a band of Coomassie-stained protein at the interface between the stacking and resolving gels. These bands were excised and subjected to in-gel digestion according to Shevchenko et al. ${ }^{36}$ Peptide mixtures were de-salted using $\mathrm{C}_{18}$ Zip-tips and analysed using Label-free quantitative proteomics (Thermo Q-Exactive LC-MS). Data analysis was performed using MaxQuant with Perseus for data organisation and statistical analysis. ${ }^{9,32}$

\section{Results}

\section{DTG chelates $\mathrm{Zn}^{2+}$ in vitro}

High resolution mass spectrometry, spectrophotometry, and chemical and enzyme assays were used to investigate the formation of a complex between DTG and $\mathrm{Zn}^{2+}$. Following TCEP-mediated reduction of gliotoxin and $\mathrm{Zn}^{2+}$ addition, negative mode MS analysis revealed the presence of a $\mathrm{Zn}$ [dithiolate gliotoxin] complex with $\mathrm{m} / \mathrm{z}=424.93851$, corresponding to a $\mathrm{Cl}^{-}$adduct of the metal chelate (Fig. $2 \mathrm{~A}$ and Fig. S1, ESI $\dagger$ ). Furthermore, DTG also competitively dissociated $\mathrm{Zn}^{2+}$ from a $\mathrm{Zn}\left[\left(4-(2-\text {-pyridylazo)-resorcinol })_{2}\right] \mathrm{Zn}(\mathrm{PAR})_{2}\right.$ complex, whereby DTG $(60-300 \mu \mathrm{M})$ addition resulted in a corresponding decrease in $A_{493 \mathrm{~nm}}$ of $\mathrm{Zn}(\mathrm{PAR})_{2}$, corresponding to $\mathrm{Zn}^{2+}$ chelation (Fig. 2B). Relevantly, gliotoxin had no effect on $\mathrm{Zn}(\mathrm{PAR})_{2}$ interaction which confirmed the specific role of the dithiol moiety of reduced gliotoxin in chelation (Fig. S2, ESI $\dagger$ ). To investigate the effect of $\mathrm{Zn}^{2+}$ on the enzymatic $S$-methylation of DTG, a GtmA activity assay was performed. GtmA bis-thiomethylates DTG to form BmGT using SAM as the methyl source (Fig. 1). ${ }^{9}$ Gliotoxin $S$-methylation occurs in a sequential manner, with mono-methylated species (MmGT) appearing initially, followed by formation of BmGT. ${ }^{9,15,37} \mathrm{Zn}^{2+}$ inhibits GtmA-mediated thiomethylation of gliotoxin in vitro in a concentration-dependent manner, most likely due to an inability to recognise and bind $\mathrm{Zn}^{2+}$ [DTG] (Fig. 2C). Support for DTG thiol protection by $\mathrm{Zn}^{2+}$ coordination was provided by an alkylation assay. Although IAA modifies DTG to alkylated gliotoxin, $\mathrm{Zn}^{2+}$ also inhibits alkylation of DTG which further strengthens the concept of thiol occlusion via $\mathrm{Zn}^{2+}$ chelation (Fig. 2D and Fig. S3, ESI $\dagger$ ).

\section{DTG inhibits AP by $\mathrm{Zn}^{2+}$ chelation}

To investigate the ability of DTG to inhibit the activity of a zincdependent metalloenzyme, AP activity assays were carried out. Gliotoxin was reduced to DTG as described above and confirmed by RP-HPLC (data not shown). DTG inhibited AP in a dosedependent manner (0-150 $\mu \mathrm{M}$ DTG) and time-dependent manner (Fig. 3A and Fig. S4, ESI $\dagger$ ). Solvent controls (containing TCEP and methanol) did not show any significant AP inhibition. While $50 \mu \mathrm{M}$ DTG significantly inhibited AP activity $(p<0.001)$, preincubation of DTG $(50 \mu \mathrm{M})$ with $\mathrm{Zn}^{2+}(25 \mu \mathrm{M}-1 \mathrm{mM})$ alleviated DTG-associated AP inhibition (Fig. 3B). The $\mathrm{Zn}^{2+}$ chelator TPEN was also tested, but only produced a minor decrease in AP activity (11\%) when used at the same concentration as DTG $(50 \mu \mathrm{M})$ (Fig. 3C). EDTA (5 mM), a metal ion chelator, inhibited AP activity by approx. 30-40\% (Fig. S5, ESI $\dagger$ ). AP activity was not significantly inhibited by $150 \mu \mathrm{M}$ GT, $50 \mu \mathrm{M}-5 \mathrm{mM}$ of the cellular reductant GSH or $50 \mu \mathrm{M}-1 \mathrm{mM}$ of the thiol-containing reductant DTT (Fig. S5, ESI $\dagger$ ). Lack of inhibition by GT, TCEP, GSH or DTT 
A.

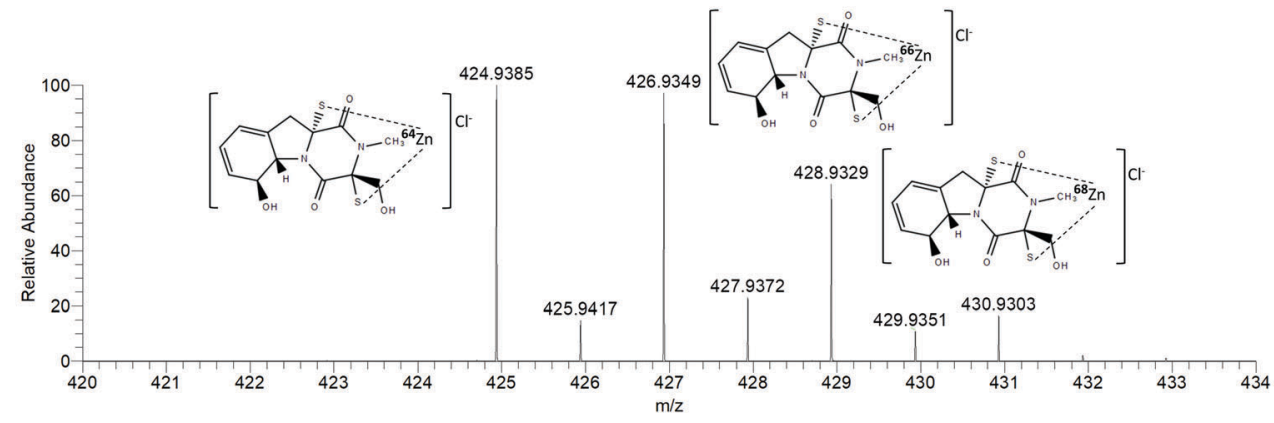

B.
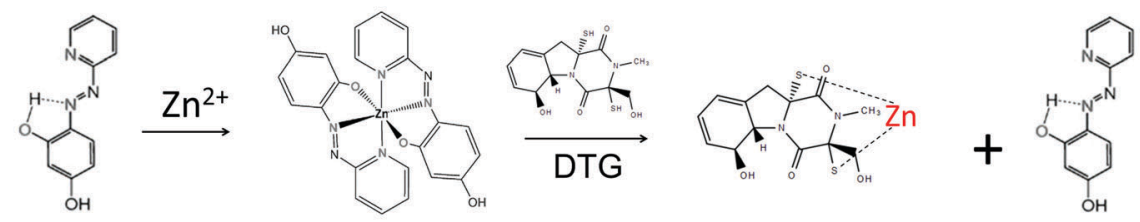

PAR

$\mathrm{Zn}(\mathrm{PAR})_{2}$

Zn:DTG

PAR

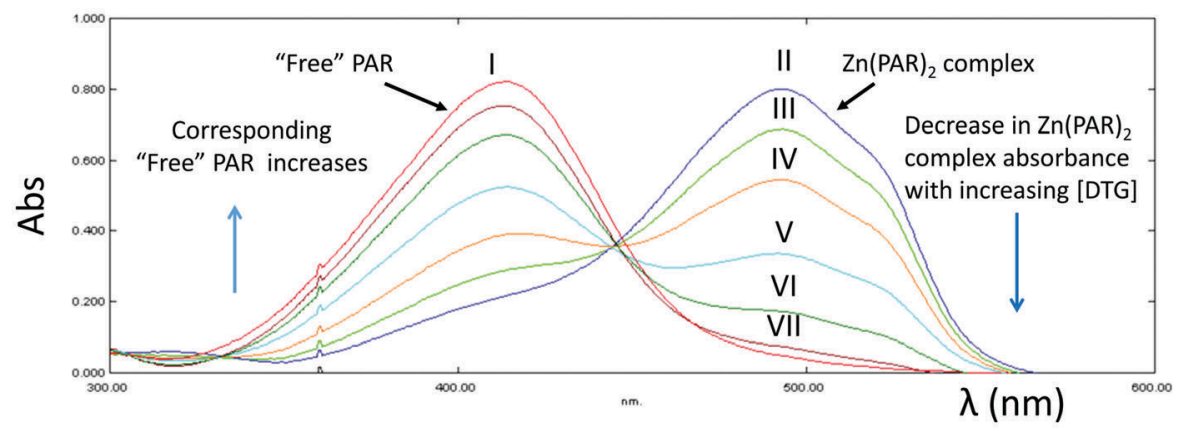

C.

D.
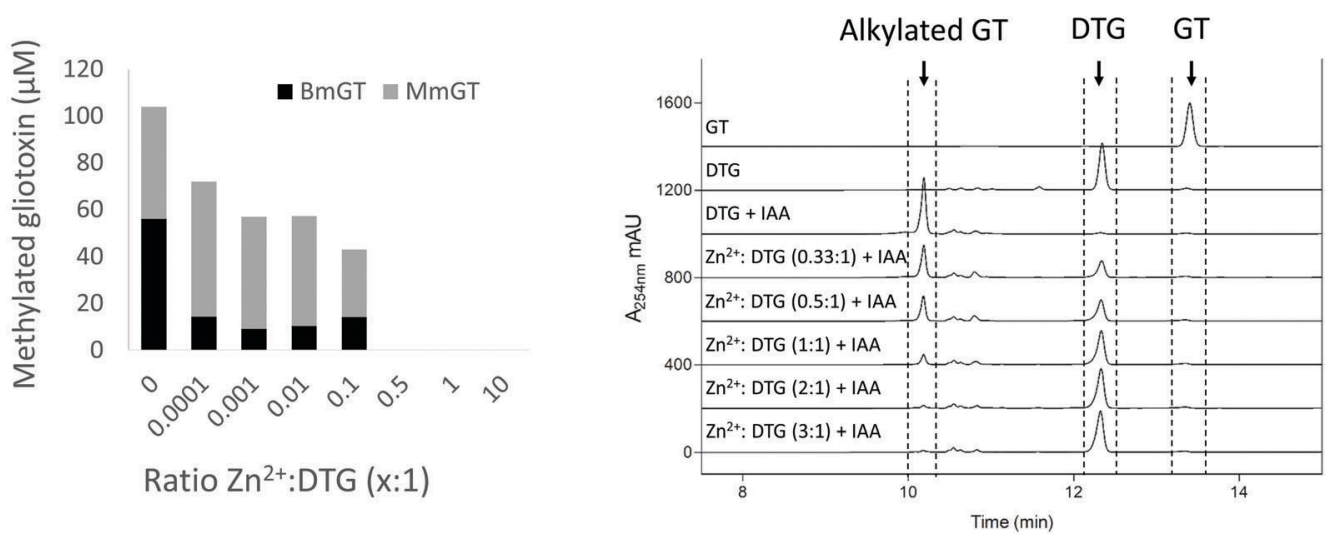

Fig. 2 Characterisation of DTG as a $\mathrm{Zn}^{2+}$ chelator. (A) Dithiolate gliotoxin complexed with $\mathrm{Zn}^{2+}\left(\mathrm{Cl}^{-}\right.$adduct) with accompanying isotopic analysis in negative ion mode MS (direct injection). Structure of DTG:Zn complex is depicted with positioning of the metal ion between the two thiolates, although exact coordination with other groups is unknown. (B) DTG chelates $\mathrm{Zn}^{2+}$ from $\mathrm{Zn}(\mathrm{PAR})_{2}\left(\mathrm{Zn}(\mathrm{PAR})_{2} \mathrm{p} K_{\mathrm{d}}=12.15\right)^{44}$ in a concentration-dependent manner. Overlaid UV-vis profiles of PAR alone (l; red), and Zn(PAR $)_{2}$ (Il; blue). DTG added in increased concentration to $Z n(P A R)_{2} 1-5$ molar equivalents of oxidised gliotoxin to $\mathrm{Zn}^{2+} ;$ III-VII, respectively. Decrease in $A_{493 \mathrm{~nm}}$ is accompanied by increase in $A_{413} \mathrm{~nm}$ as free PAR is released. (C) $\mathrm{Zn}^{2+}$ inhibits GtmA-mediated methylation of DTG in a concentration dependent manner. $\mathrm{Zn}^{2+}$ was included in the methylation assay at a molar ratio ranging from 0.0001 to $10: 1$ (DTG). A control containing no $\mathrm{Zn}^{2+}$ was included. Concentration $(\mu \mathrm{M})$ of BmGT and MmGT formed after 5 min was determined by RP-HPLC. (D) $\mathrm{Zn}^{2+}$ inhibits IAA-mediated alkylation of DTG in a concentration-dependent manner. RP-HPLC analysis (detection at $254 \mathrm{~nm}$ ) reveals the inhibitory effect of $Z \mathrm{n}^{2+}$ on DTG alkylation.

strongly infers that inhibition is not caused by AP disulphide bridge cleavage or thiol modification. Zinc addition for $30 \mathrm{~min}$ reverses DTG-induced inhibition of AP, which further implicates $\mathrm{Zn}^{2+}$ chelation as the mechanism of inhibition (Fig. S6, ESI†). 


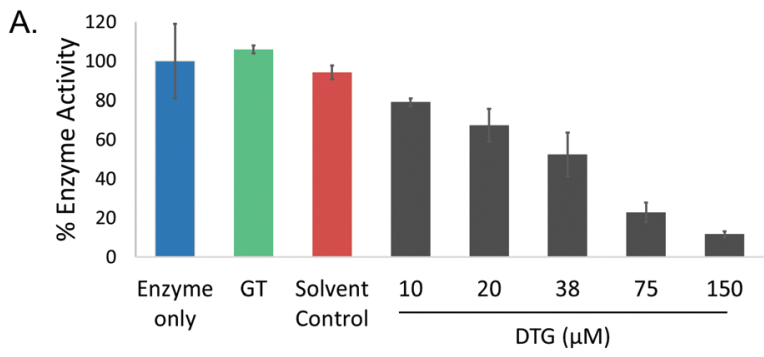

B.

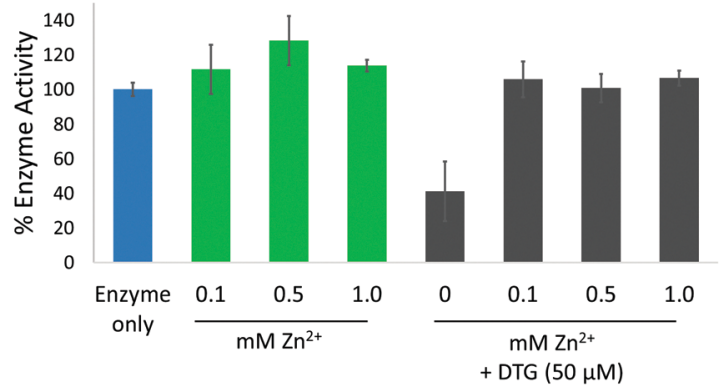

C.

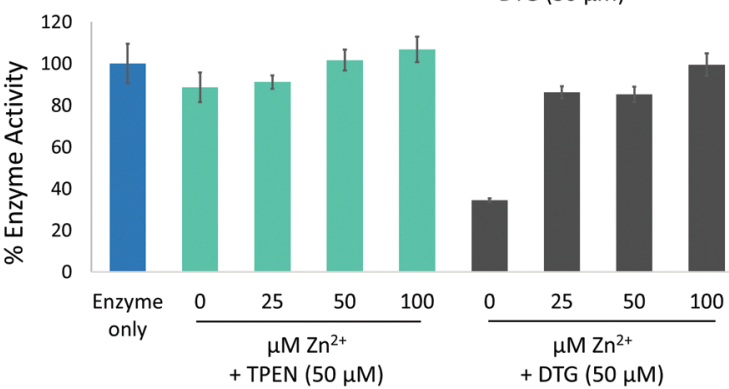

Fig. 3 DTG inhibits AP activity by $\mathrm{Zn}^{2+}$ chelation. (A) Dose-dependent (10-150 $\mu \mathrm{M}$ DTG) inhibition of AP activity, with $\mathrm{IC}_{50}=38 \mu \mathrm{M}$ DTG. Neither GT or the solvent control ( $12.5 \mathrm{mM}$ TCEP in methanol) inhibit AP activity. (B) Pre-incubation of DTG with $\mathrm{Zn}^{2+}(0.1,0.5$ and $1 \mathrm{mM})$ prevents DTGmediated enzyme inhibition. (C) TPEN $(50 \mu \mathrm{M})$ has no significant impact on AP activity ( $89 \%$ activity compared to control). Pre-incubation of DTG with $\mathrm{Zn}^{2+}(25-50 \mu \mathrm{M})$ significantly recovered AP activity to $86 \%$ of the control.

\section{Impact of $\mathrm{Zn}^{2+}$ exposure on A. fumigatus $\Delta$ gliT and} $\Delta g l i T: \Delta g t m A$, in the presence of exogenous gliotoxin

In order to determine whether $\mathrm{Zn}^{2+}$ had an impact on gliotoxinassociated growth inhibition, plate assays were carried out using A. fumigatus strains deficient in enzymes that use DTG as their substrate, $\Delta g l i T: \Delta g t m A$ and $\Delta g l i T$. Severe radial growth inhibition of $A$. fumigatus $\Delta g l i T: \Delta g t m A$ in the presence of gliotoxin $(15 \mu \mathrm{M})^{15}$ (Fig. 4A) was significantly relieved $(p<$ $0.005)$ in the presence of $1-10 \mu \mathrm{M} \mathrm{Zn}^{2+}$, and relief of gliotoxinmediated growth inhibition was maintained up to $50 \mu \mathrm{M} \mathrm{Zn}^{2+}$. Radial growth of $A$. fumigatus $\Delta g l i T:: \Delta g t m A$ was unaffected by $\mathrm{Zn}^{2+}(1-50 \mu \mathrm{M})$. Higher concentrations of $\mathrm{Zn}^{2+}$ significantly inhibited the growth of both A. fumigatus $\Delta$ gliT:: $\Delta$ gtmA $(100 \mu \mathrm{M}-1$ mM; Fig. 4) and A. fumigatus $\Delta g l i T$ (1-2 mM; Fig. S7, ESI $\dagger$ ). This correlates with a decrease in the rescue effect of $\mathrm{Zn}^{2+}$ on gliotoxinassociated growth inhibition in A. fumigatus $\Delta g l i T: \Delta g t m A$. The combination of gliotoxin $(15-30 \mu \mathrm{M})$ and excess $\mathrm{Zn}^{2+}(1-2 \mathrm{mM})$ produced further inhibition of radial growth of A. fumigatus $\Delta g l i T$ at $96 \mathrm{~h}(p<0.005)$ compared to the growth reduction observed in either the presence of $\mathrm{Zn}^{2+}$ or gliotoxin alone (Fig. S7, ESI $\dagger$ ).
A.
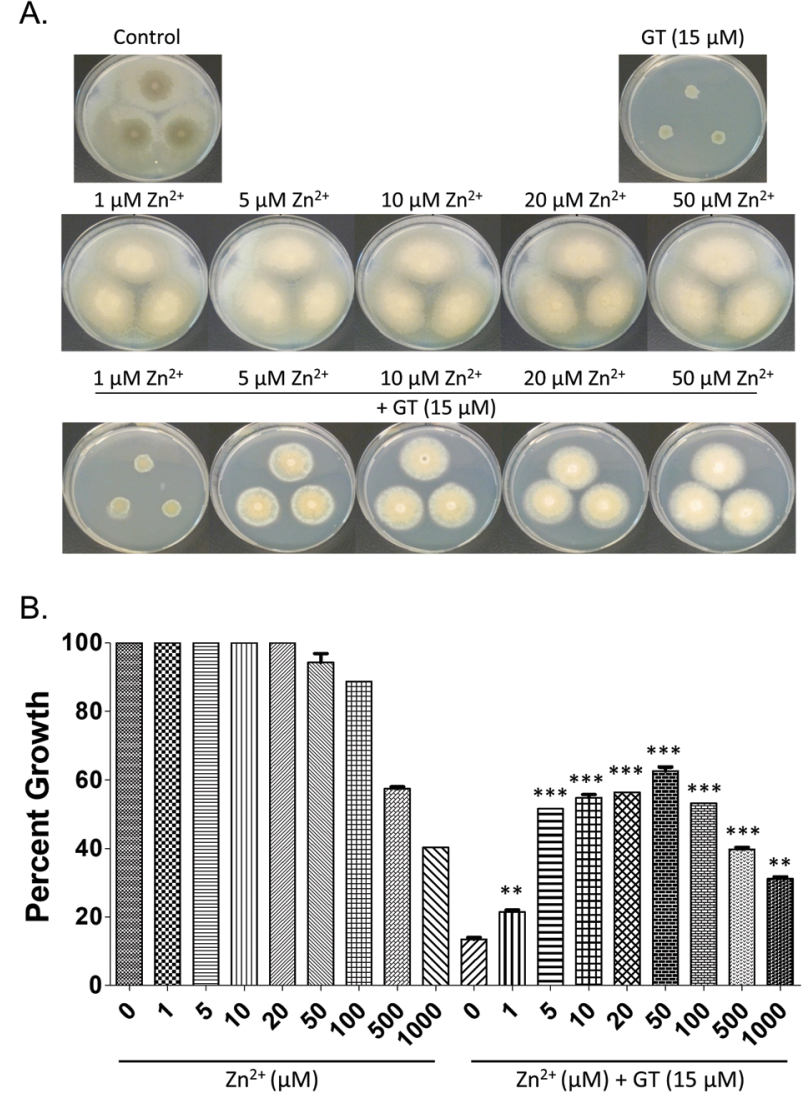

Fig. 4 (A) Potent growth inhibitory effect of gliotoxin $(15 \mu \mathrm{M})$ on $A$. fumigatus $\Delta g l i T:: \Delta g t m A$ is significantly $(p<0.005)$ reversed by co-addition of $\mathrm{Zn}^{2+}$ $(1-50 \mu \mathrm{M}) \cdot \mathrm{Zn}^{2+}(0-50 \mu \mathrm{M})$ has a negligible effect on mutant growth. (B) Graphical representation of same in terms of relative growth percentages. Note that higher $\mathrm{Zn}^{2+}$ levels $(100 \mu \mathrm{M}-1 \mathrm{mM})$ result in dissipation of the relief, in line with $\mathrm{Zn}^{2+}$-associated toxicity noted in controls.

\section{$\mathrm{Zn}^{2+}$ augments gliotoxin uptake and efflux in $A$. fumigatus wild-type and $\Delta g l i T: \Delta g t m A$}

Previous studies have revealed that exogenous gliotoxin is sequestered by A. fumigatus. ${ }^{38}$ To further explore the interaction between $\mathrm{Zn}^{2+}$ and gliotoxin in vivo, both A. fumigatus wild-type and $\Delta g l i T: \Delta g$ tmA were exposed to gliotoxin $(15 \mu \mathrm{M})$ for $3 \mathrm{~h}$ in the presence and absence of $\mathrm{Zn}^{2+}(1 \mathrm{mM})$. In all conditions uptake of gliotoxin by A. fumigatus was evident by decreasing levels detected in culture supernatants across the incubation times, and corresponding increases in intracellular gliotoxin concentration (Fig. S8, ESI $\dagger$ ). Fig. S8A-D (ESI $\dagger$ ) show that excess $\mathrm{Zn}^{2+}$ augmented gliotoxin uptake in both A. fumigatus wild-type and $\Delta g l i T:: \Delta g t m A$. In the presence of $\mathrm{Zn}^{2+}(1 \mathrm{mM})$, with significantly less gliotoxin detected in A. fumigatus wild-type culture supernatants 30 min after addition (Fig. S8A-C; $p<0.05$, ESI $\dagger$ ). $\mathrm{Zn}^{2+}$ effected a more marked response in A. fumigatus $\Delta g l i T: \Delta g t m A$, with a significant decrease in extracellular gliotoxin levels at every time point (15-180 min; Fig. S8B; $p<0.05$, ESI $\dagger$ ). When excess $\mathrm{Zn}^{2+}$ was present in the culture medium, initial rates of gliotoxin uptake increased from $38.32 \pm 5$ to $55.04 \pm 8.78 \mathrm{ng} \mathrm{min}{ }^{-1} \mathrm{ml}^{-1}$ of culture (mean \pm SEM) in A. fumigatus wild-type and from

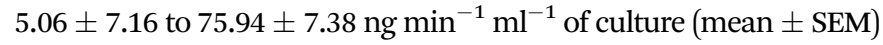


in $\Delta g l i T:$ :gtmA. Commensurate increases in intracellular gliotoxin (ng/100 mg mycelia) were observed in both A. fumigatus wildtype and $\Delta g l i T:: \Delta g t m A$, in the presence of $\mathrm{Zn}^{2+}$ (Fig. S8D, ESI $\dagger$ ). Intracellular levels of gliotoxin were significantly increased in $A$. fumigatus wild-type upon $\mathrm{Zn}^{2+}$ co-addition $(p<0.01)$, likely due to inhibition of GtmA-catalysed BmGT formation and efflux. Elevated intracellular gliotoxin levels in $\Delta g l i T: \Delta g t m A$ correlated with an increased rate of gliotoxin uptake induced by $\mathrm{Zn}^{2+}$ (Fig. S8, ESI $\dagger$ ). Intracellular DTG was not detectable due to either spontaneous intracellular or extraction-associated oxidation.

\section{LFQ proteomic analysis reveals that $\mathrm{Zn}^{2+}$ alters the effect of gliotoxin on A. fumigatus $\Delta$ gliT}

To further investigate the nature of the combinatorial inhibition of A. fumigatus $\Delta$ gliT during simultaneous exposure to $\mathrm{Zn}^{2+}$ and gliotoxin, compared to gliotoxin alone, comparative LFQ proteomic analysis was carried out. Overall, 47 proteins exhibited unique presence and 23 proteins were significantly increased in abundance in $A$. fumigatus $\Delta g l i T$ upon combinatorial exposure $\left(\mathrm{Zn}^{2+} / \mathrm{GT}\right)$ compared to gliotoxin only (Table S1, ESI $\dagger$ ). Conversely, 45 proteins were absent and 10 proteins showed significantly reduced abundance in A. fumigatus $\Delta g l i T$ upon combinatorial exposure compared to gliotoxin only (Table S1, ESI $\dagger$ ). Functional analysis revealed that zinc-ion binding proteins were significantly enriched (8/70 proteins; $p=0.005)$ among proteins with elevated abundance or uniquely detected in the presence of $\mathrm{Zn}^{2+} / \mathrm{GT}$ compared to gliotoxin alone (Table 1 and Fig. S9, ESI $\dagger$ ). Notably, secondary metabolism-associated proteins were altered in abundance, or demonstrated qualitative changes in the combined condition $\left(\mathrm{Zn}^{2+} / \mathrm{GT}\right)$ compared to gliotoxin only (Table 2). These included the ferricrocin synthetase SidC, which was repressed by gliotoxin, but not by the combined condition, as were four members of the fumagillin biosynthetic cluster (Table 2 and Table S1, ESI $\dagger$ ). Consequently, when A. fumigatus was grown in gliotoxin-producing conditions, $\mathrm{Zn}^{2+}$ caused a significant increase in fumagillin levels even at lower levels $\left(0.027 \mathrm{mM} \mathrm{Zn}^{2+} ; p<0.001\right)$ (Fig. S10, ESI $\dagger$ ).
Low affinity zinc transporter ZrfB, which is ZafA-dependent and normally induced by zinc depletion, was undetectable in the combinatorial exposure condition, which suggests a zinclimiting environment in gliotoxin-only exposure (Table 1). Likewise, allergen AspF2 which is expressed under zinc-limiting conditions, and shares a divergent promoter with $z r f C$, was absent upon co-exposure. ${ }^{39}$ It was also observed that GliM, a component of the gliotoxin biosynthetic capacity was absent, which infers that gliotoxin biosynthesis may be attenuated in the combinatorial exposure scenario (Table 2). Indeed, $\mathrm{Zn}^{2+}$ presence completely abrogated gliotoxin biosynthesis in CzapekDox media (Fig. S10, ESI $\dagger$ ). These observations pertaining to impeded gliotoxin biosynthesis are further supported by the absence of GpgA (AFUA_1G05210), a G-protein coupled receptor subunit, previously shown to be essential for gliotoxin production in A. fumigatus. ${ }^{40}$ It is also notable that the nonribosomal peptide synthetase NRPS8/Pes3 ${ }^{41}$ (AFUA_5G12730) was absent following co-exposure to $\mathrm{Zn}^{2+}$ and gliotoxin, which suggests that it may contribute to adaptation to zinc-limiting conditions.

Gliotoxin exposure induces elevated GtmA abundance in A. fumigatus $\Delta g l i T,{ }^{9}$ and Manzanares-Miralles et al. reported that gliotoxin induces significantly increased abundance of the GtmA ortholog in Aspergillus niger, in which the gli cluster is absent. ${ }^{37}$ Interestingly, while $\mathrm{Zn}^{2+}$ exposure alone had no significant effect on the abundance of GtmA in A. fumigatus, combinatorial exposure with gliotoxin resulted in significantly elevated GtmA abundance $(18.8$-fold and $p<0.01)$ compared to that in the presence of gliotoxin only (Table 2). Allied to GtmA activity data (Fig. 2C), this suggests that in vivo chelation of $\mathrm{Zn}^{2+}$ by DTG may prevent substrate access to GtmA, thereby resulting in a further increased abundance of the enzyme (Fig. 5A).

\section{Manifestation of heat-induced in vitro protein aggregation in A. fumigatus mycelial lysates, specifically by DTG}

Inhibition of $\mathrm{Zn}^{2+}$-dependent enzyme activities, combined with the observed in vivo interplay between the divalent metal cation

Table 1 Zinc associated proteins with differential abundance, or uniquely detected, between the combination condition $\left(\mathrm{Zn}^{2+} / \mathrm{GT}\right)$ and the gliotoxin only control

\begin{tabular}{|c|c|c|c|c|}
\hline Protein description & $\log _{2}$ fold change ${ }^{a}(p$ value $)$ & Uniquely detected $^{b}$ & Peptides & Gene IDs (AFUA_) \\
\hline \multicolumn{5}{|l|}{ Zinc ion binding } \\
\hline Zinc knuckle domain protein (Byr3), putative & $-1.33(0.021)$ & & 9 & $1 \mathrm{G} 07630$ \\
\hline Rho GTPase activator activity Rga & $\mathrm{N} / \mathrm{A}$ & $\mathrm{Zn}^{2+} / \mathrm{GT}$ & 4 & $1 \mathrm{G} 12680$ \\
\hline Putative zinc-binding dehydrogenase family oxidoreductase & $1.55(0.0018)$ & & 16 & $1 \mathrm{G} 15610$ \\
\hline Putative formaldehyde dehydrogenase & $1.54(0.0027)$ & & 15 & $2 \mathrm{G} 01040$ \\
\hline Putative carbonic anhydrase CafA & $1.65(0.0029)$ & & 12 & $4 \mathrm{G} 11250$ \\
\hline C-x8-C-x5-C-x3-H type zinc finger & N/A & $\mathrm{Zn}^{2+} / \mathrm{GT}$ & 5 & $4 \mathrm{G} 13910$ \\
\hline Putative zinc-dependent alcohol dehydrogenase AlcC & $1.62(0.0004)$ & & 30 & $5 \mathrm{G} 06240$ \\
\hline Cytidine deaminase, zinc ion binding activity & N/A & $\mathrm{Zn}^{2+} / \mathrm{GT}$ & 2 & $7 \mathrm{G} 01040$ \\
\hline Zinc knuckle nucleic acid binding protein, putative & N/A & GT & 2 & $7 \mathrm{G} 02190$ \\
\hline Putative carbonate dehydratase, zinc ion binding activity & $1.67(0.0041)$ & & 7 & $8 G 06554$ \\
\hline \multicolumn{5}{|l|}{ Zinc homeostasis } \\
\hline Low affinity plasma membrane zinc transporter ZrfB & N/A & GT & 3 & $2 \mathrm{G} 03860$ \\
\hline Allergen Aspf2 Aspf2 & $\mathrm{N} / \mathrm{A}$ & GT & 7 & 4G09580 \\
\hline
\end{tabular}

${ }^{a}$ Negative values indicate protein was decreased in abundance in combination treatment $\left(\mathrm{Zn}^{2+} / \mathrm{GT}\right)$ compared to the gliotoxin only treatment, while positive values indicate an increase in abundance. ${ }^{b}$ Uniquely detected: protein uniquely identified in at least 2 biological replicates of either gliotoxin-only treated cultures or the combination condition $\left(\mathrm{Zn}^{2+} / \mathrm{GT}\right)$. 
Table 2 Secondary metabolism-related proteins with differential abundance, or uniquely detected, between the combination condition ( $\left.\mathrm{Zn}^{2+} / \mathrm{GT}\right)$ and the gliotoxin-only control

\begin{tabular}{|c|c|c|c|c|c|}
\hline \multirow[t]{2}{*}{ Gliotoxin } & Unknown function protein GliH & & GT & 3 & $6 \mathrm{G} 09745$ \\
\hline & Gliotoxin thiomethyltransferase GtmA & $4.2361(0.0052)$ & & 18 & $2 \mathrm{G} 11120$ \\
\hline NRPS8 (unknown) & NRPS8/Pes3 & & GT & 3 & $5 \mathrm{G} 12730$ \\
\hline Ferricrocin & NRPS involved in ferricrocin siderophore biosynthesis SidC & & $\mathrm{Zn}^{2+} / \mathrm{GT}$ & 5 & $1 \mathrm{G} 17200$ \\
\hline \multirow[t]{2}{*}{ Fumagillin } & Putative alpha/beta hydrolase FmaC & & $\mathrm{Zn}^{2+} / \mathrm{GT}$ & 11 & $8 \mathrm{G} 00380$ \\
\hline & Putative iron-dependent oxygenase FmaF & & $\mathrm{Zn}^{2+} / \mathrm{GT}$ & 9 & $8 \mathrm{G} 00480$ \\
\hline
\end{tabular}

${ }^{a}$ Uniquely detected: protein uniquely identified in at least 2 biological replicates of either gliotoxin-only treated cultures or the combination condition $\left(\mathrm{Zn}^{2+} / \mathrm{GT}\right)$.

and DTG in A. fumigatus, led us to further investigate the interaction between DTG and A. fumigatus proteins. DTG-associated protein destabilisation was investigated by exposing complex lysates to either DTG or a mixture of $\mathrm{Zn}^{2+}$ and DTG, followed by heat treatment. Exposure of $A$. fumigatus mycelial protein lysates to TCEP/methanol, DTG or a mixture of $\mathrm{Zn}^{2+}$ and DTG followed by SDS-PAGE analysis revealed near-identical electrophoretic patterns in the resolving gel (Fig. 5B). However, uniquely, following protein lysate exposure to DTG, and subsequent heat treatment $\left(50{ }^{\circ} \mathrm{C} / 30 \mathrm{~min}\right)$, either protein aggregation or an inability to
A.
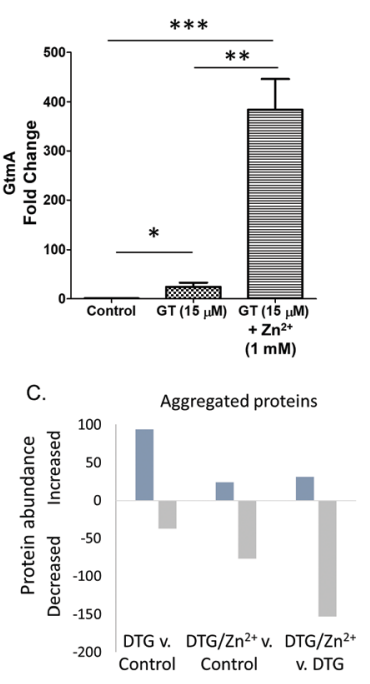

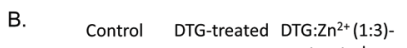

B. Control DTG-treated DTG:Zn ${ }^{2+}(1: 3)$ -

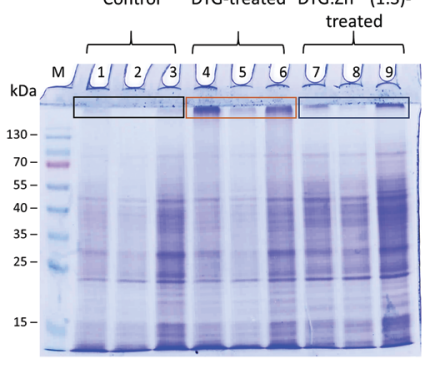

D.

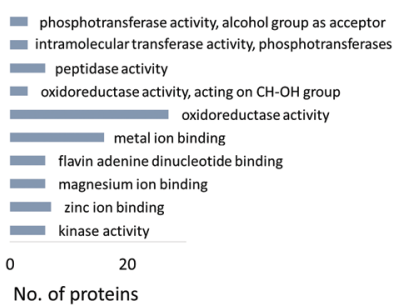

Fig. 5 (A) Fold change in GtmA abundance following gliotoxin (GT: $15 \mu \mathrm{M}$ ) and gliotoxin $\& \mathrm{Zn}^{2+}(15 \mu \mathrm{M} \& 1 \mathrm{mM}$, respectively) exposure compared to controls in A. fumigatus $\Delta$ gliT. (B) SDS-PAGE analysis of 3 independently prepared A. fumigatus protein lysates. Lanes 1-3: negative controls: protein lysates treated with TCEP/methanol only. Lanes 4-6: protein lysates treated with DTG. Lanes 7-9: protein lysates treated with DTG: $\mathrm{Zn}^{2+}(1: 3) . \mathrm{M}$, molecular mass marker. Protein aggregation is evident (boxes) following DTG-exposure. (C) Number of proteins with increased or decreased abundance (qualitative and quantitative) in aggregates recovered from control, DTG or combined DTG/Zn ${ }^{2+}$ treatments. (D) Functional analysis (FungiFun2) showing GO molecular function categories significantly enriched $(p<0.05)$ among proteins with increased abundance in DTGinduced aggregates. Arranged in order of ascending $p$ value. disaggregate unfolded proteins was observed (Fig. 5B). Mass spectrometry-based analysis of the proteins retained at the interface between the stacking and resolving gel identified 551 proteins in total from the three conditions tested. Label-free proteomics revealed 94 proteins uniquely detected or significantly elevated in the aggregates following DTG pre-treatment, relative to the control (Fig. 5C and Table S2, ESI†). DTG addition to A. fumigatus lysates elicits an overall increase in aggregated proteins compared to the controls. Functional analysis revealed a significant number of proteins with oxidoreductase activity $(n=27, p=0.019)$, metal ion binding $(n=16, p=0.024)$ and zinc ion binding $(n=7, p=0.047)$ showed increased aggregation in response to DTG treatment (Fig. 5D). Notably, pre-incubation of DTG with $\mathrm{Zn}^{2+}$ prevented this aggregation in the case of $77 \%$ of the DTG-responsive proteins (72/94 proteins), whereby the combinatorial condition lead to significantly lower levels of protein aggregation compared to DTG treatment $(p<0.05)$. Additional stabilisation was observed in the combinatorial condition, as 77 proteins showed lower abundance in the aggregates compared to the control condition (Fig. 5C). Excess $\mathrm{Zn}^{2+}$ used in the pre-mixed $\mathrm{DTG} / \mathrm{Zn}^{2+}$ treatment could contribute to this additional stabilising effect.

Among the proteins affected by DTG-induced aggregation, was the zinc-dependent alcohol dehydrogenase AlcC, which was only detected in aggregates from lysates pre-incubated with DTG, indicating co-addition of $\mathrm{Zn}^{2+}$ prevented DTG-induced aggregation of this protein. Another protein detected exclusively in aggregates induced by DTG was the putative farnesyltransferase beta subunit Ram1 (AFUA_4G10330) which contains a C-terminal $\mathrm{Zn}^{2+}$ binding pocket, within the active site. ${ }^{42,43}$ A number metallopeptidases were also increased or uniquely detected in DTGinduced aggregates (AFUA_6G09190, AFUA_4G07910, MepB), as well as the zinc-dependent methionine synthase MetH/D, while co-addition of $\mathrm{Zn}^{2+}$ generated aggregation profiles in line with the control.

Overall, these data suggest that DTG may chelate $\mathrm{Zn}^{2+}$ from selected cellular proteins thereby inducing protein unfolding and consequently resulting in temperature-induced aggregation. It is also possible that DTG inhibits selected components of the proteasome-mediated recognition and/or digestion of protein aggregates; which results in their persistence in DTG-treated 
lysates. Finally, it is likely that some proteins detected in the aggregates may be present as a result of non-specific physical entrapment, however, these putative, non-specifically aggregated proteins are resistant to the dissolution effects of SDS solubilisation buffer and heat $\left(95^{\circ} \mathrm{C} / 4 \mathrm{~min}\right)$.

\section{Discussion}

Herein, we provide evidence that DTG is a $\mathrm{Zn}^{2+}$-chelator. We also reveal $\mathrm{Zn}^{2+}$-metalloenzyme inhibition specifically by DTG, and not by gliotoxin or other reducing agents (DTT or GSH). This suggests $\mathrm{Zn}^{2+}$ chelation, as well as disulphide bridge cleavage or thiol modification, as a key mode of enzyme inhibition by DTG. We propose that DTG, acting as a $\mathrm{Zn}^{2+}$-chelator, can significantly inhibit growth of A. fumigatus completely deficient in essential oxidation or thiomethylation activities. Unbiased LFQ proteomics reveals that $\mathrm{Zn}^{2+}$ can significantly modify the nature and extent of protein abundance alterations caused by $A$. fumigatus $\Delta g l i T$ exposure to gliotoxin. This important revelation confirms in vivo interaction between both molecular species. Moreover, additional LFQ proteomic data reveal that in vitro, DTG can cause specific protein aggregation, manifested by heat instability, possibly due to structural alteration to known $\mathrm{Zn}^{2+}$-dependent enzymes. These unexpected observations open a new front in our exploration of the metallo-metabolome in fungi, and possibly other species.

High resolution, negative mode MS revealed that DTG complexes $\mathrm{Zn}^{2+}$ and exhibits a monoisotopic peak with $\mathrm{m} / \mathrm{z} 424.93749$, which equates to a single $\mathrm{Zn}^{2+}$ [DTG] complex detected as a $\mathrm{Cl}^{-}$adduct $\left[\left(\mathrm{DTG}+{ }^{64} \mathrm{Zn}\right)-2 \mathrm{H}+\mathrm{Cl}\right]^{-}$. Previous work by Woodcock et al. proposed the existence of a similar adduct $(\mathrm{m} / \mathrm{z} 427)$, following $\mathrm{NaBH}_{4}$-mediated reduction. ${ }^{24}$ Since no spectra were provided, it is not possible to ascertain the origin of the different observed $\mathrm{m} / \mathrm{z}$ values, although it seems likely that Woodcock et al. reported the average $m / z$ for the compound or the $m / z$ of the base peak $\left[\left(\mathrm{DTG}+{ }^{66} \mathrm{Zn}\right)-2 \mathrm{H}+\mathrm{Cl}\right]^{-}$, rather than the monoisotopic peak. ${ }^{24} \mathrm{In}$ addition, we have found that DTG efficiently chelates $\mathrm{Zn}^{2+}$ from $\mathrm{Zn}(\mathrm{PAR})_{2}(60 \mu \mathrm{M})$, in a dose-dependent manner from 60 to $300 \mu \mathrm{M}$ DTG. Given that Kocyla et al. have proposed an effective $\mathrm{p} K_{\mathrm{d}}$ of 12.15 at $\mathrm{pH} 7.4$ for $\mathrm{Zn}(\mathrm{PAR})_{2}$, it is clear that the affinity of DTG for $\mathrm{Zn}^{2+}$ must equate to, or exceed, this value as $\mathrm{Zn}^{2+}$ is removed from the $\mathrm{Zn}(\mathrm{PAR})_{2}$ complex when equimolar amounts of DTG are added to it. ${ }^{44}$ However, it is not ideal to compare these complexes directly due to differences in stoichiometry. Chan et al. also deployed a PARbased assay system, which involved chelation of $\mathrm{Zn}^{2+}$ from $\mathrm{Zn}(\mathrm{PAR})_{2}$, and subsequent formation of stable complexes to reveal that $\mathrm{Zn}^{2+}$ is chelated by dithiol holomycin (Fig. 1; termed red-holomycin in Chan et al.) with high affinity. ${ }^{30}$ Davis et al. previously revealed and characterised alkylation of DTG using $5^{\prime}$-iodoacetamidofluorescein. ${ }^{45}$ In the present study, we observed that IAA-mediated alkylation of DTG was inhibited by $\mathrm{Zn}^{2+}$, which further underpins our proposal that a $\mathrm{Zn}[\mathrm{DTG}]$ complex is formed via thiolate coordination and is stable under in vitro conditions used.

DTG acts as a potent inhibitor of the $\mathrm{Zn}^{2+}$-dependent enzyme, AP. Previous studies have reported the inhibitory effects of gliotoxin on mammalian $\mathrm{Zn}^{2+}$-dependent enzymes, without attributing this activity to zinc chelation. ${ }^{16,17}$ Vigushin et al. studied the inhibition of $\mathrm{Zn}^{2+}$-dependent farnesyltransferase (FTase) and geranyltransferase (GGTase) I by gliotoxin, proposing thiol modification of these enzymes as a possible mechanism of action. Importantly, the authors noted that these assays required the reductant DTT, which aligns with our observations of the inhibition of $\mathrm{Zn}^{2+}$-dependent metalloenzymes (i.e., AP) by DTG rather than gliotoxin. Our data also provides an alternative explanation for previous observations which suggested that reducing agents enhanced the inhibitory activity of gliotoxin against a $\mathrm{Zn}^{2+}$-dependent equine $\mathrm{ADH}{ }^{16}$ Although these authors posited a redox explanation, it is equally plausible that $\mathrm{Zn}^{2+}$ chelation by DTG effected equine ADH inhibition. This accords with our observations that prior incubation of DTG with $\mathrm{Zn}^{2+}$ prevents inactivation of AP, and also that DTGassociated AP inhibition can be rescued by subsequent addition of $\mathrm{Zn}^{2+}$ (Fig. 3 and Fig. S6, ESI $\dagger$ ).

Relevantly, it has been shown that ETPs, in particular gliotoxin, block the interaction between Hypoxia Inducible Factor- $\alpha$ (HIF- $\alpha$ ) and the transcriptional coactivator p300 by a $\mathrm{Zn}^{2+}$ ejection mechanism. ${ }^{18}$ Moreover, these authors noted the antiproliferative effects of ETPs, and provide significant insight into their mechanism of action in animal cells. Cook et al. reference the $\mathrm{Zn}^{2+}$-dependency of many gliotoxin-sensitive enzymes and the $\mathrm{Zn}^{2+}$ requirement of Gliz, the transcription factor essential for gliotoxin biosynthesis. ${ }^{1,18}$ However, their proposed mechanism of action of $\mathrm{Zn}^{2+}$ ejection from p300 by gliotoxin does not take into account the presence of DTT in assay buffers. ${ }^{18}$ Thus, consequent to our observations with AP and those of Cook et al., we now speculate that it is DTG, formed due to the presence of equivalent amounts of DTT, and not gliotoxin per se, which causes $\mathrm{Zn}^{2+}$ ejection from p300. Relevantly, it has recently been elegantly demonstrated that dithiol holomycin (Fig. 1) can effect $\mathrm{Zn}^{2+}$ chelation and cause inhibition of a metallo- $\beta$-lactamase. ${ }^{30}$ Our demonstration of DTG-mediated inhibition of AP suggests that the $\mathrm{Zn}^{2+}$ chelation potential of dithiolopyrrolones, like holomycin, extends to ETPs.

Our deployment of $A$. fumigatus mutants deficient in gliotoxin self-protection $(\Delta g l i T)$ and self-protection/negative regulation of gliotoxin biosynthesis in combination $(\Delta g l i T: \Delta g t m A)$ reveal a hitherto unknown systems interaction between $\mathrm{Zn}^{2+}$ and gliotoxin biochemistry. We have observed the in vitro inhibition of GtmAmediated BmGT formation by $\mathrm{Zn}^{2+}$. This mode of inhibition appears to result from DTG chelation of $\mathrm{Zn}^{2+}$, and its subsequent unavailability as a substrate to GtmA, as opposed to direct enzyme inhibition. Interestingly, this observation is in accordance with the effect of $\mathrm{Zn}^{2+}$ ( 1 and $2 \mathrm{mM}$ ) exposure towards A. fumigatus $\Delta$ gliT, whereby combinatorial gliotoxin/ $/ \mathrm{Zn}^{2+}$ exposure significantly augments growth inhibition. In effect, we postulate that elevated levels of $\mathrm{Zn}^{2+}$ may augment intracellular $\mathrm{Zn}$ (DTG) complex formation, resulting in non-availability to GtmA, which actually significantly increases GtmA abundance (Fig. 5A). Thus, we speculate that $\mathrm{Zn}^{2+}$-mediated disruption of GtmA functionality in A. fumigatus $\Delta g l i T$ partially creates an inability to dissipate DTG, though not as absolute as pertains in A. fumigatus $\Delta g l i T: \Delta g t m A$. Indeed, A. fumigatus $\Delta g l i T:: \Delta g t m A$ presents an ideal system to explore the functionality of $\mathrm{Zn}^{2+}$-dependent systems in fungi, since the 


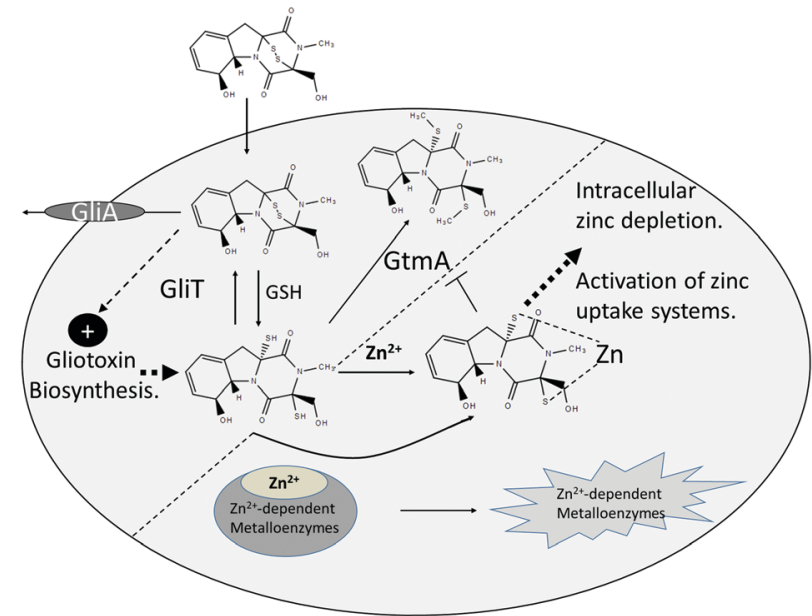

Fig. 6 Overview of the proposed mechanism and consequences of $\mathrm{Zn}^{2+}$ chelation by intracellular DTG in A. fumigatus. DTG is produced consequent to gliotoxin uptake, via GSH-mediated chemical reduction, or de novo gliotoxin biosynthesis. Under normal conditions, two enzyme systems, namely GliT-mediated oxidation and GtmA-mediated thiomethylation effect dismutation of DTG to prevent interference with intracellular zinc homeostasis. In the absence of both enzymes, elevated intracellular DTG can either chelate free $\mathrm{Zn}^{2+}$ or chelate it from intracellular $\mathrm{Zn}^{2+}$-dependent metalloenzymes, causing extreme growth inhibition. Additionally, Zn(DTG) cannot be converted to BmGT via GtmA. Either way, disruption of intracellular zinc homeostasis occurs which leads to activation of zinc uptake systems, potentially via ZafA induction of ZrfA-C expression.

organism lacks both enzymes, GliT and GtmA, which contribute to dissipation of intracellular DTG (Fig. 6), ultimately via either gliotoxin or BmGT efflux. ${ }^{15}$ The significant, though incomplete, $\mathrm{Zn}^{2+}$-mediated reversal of A. fumigatus $\Delta g l i T:: \Delta g t m A$ sensitivity to exogenous gliotoxin exposure implicates either chelation of free $\mathrm{Zn}^{2+}$ or chelation of $\mathrm{Zn}^{2+}$ from cellular metalloenzymes, by DTG as key inhibitory mechanisms (Fig. 6). To our knowledge, this is the first report of an in vivo interaction between gliotoxin biosynthesis, dysregulated DTG presence and growth inhibition due to potential interference with $\mathrm{Zn}^{2+}$-associated growth systems. Moreover, it contributes to explaining the cryptic observation of Dolan et al. that A. fumigatus $\triangle$ gliT:: $\triangle$ gtmA is the most gliotoxinsensitive mutant observed to date, ${ }^{15}$ and also why there are two distinct enzymatic activities which can prevent intracellular DTG accumulation. Overall, these data indicate the inhibitory potential of this endogenous, and potent, $\mathrm{Zn}^{2+}$ chelator in A. fumigatus in particular, and possibly microorganisms in general. Indeed, gliotoxin significantly inhibits growth of a range of fungi, ${ }^{12,46}$ and previously work has also indicated its potent anti-bacterial activity. ${ }^{47}$

It is clear that interference with intracellular DTG levels, via gliotoxin exposure to A. fumigatus $\Delta g l i T$ impacts on the fungal proteome, which in turn can be modulated by $\mathrm{Zn}^{2+}$ presence. Indeed, it has been estimated that up to 6\% (600/10000) of the A. fumigatus proteome comprises $\mathrm{Zn}^{2+}$-binding proteins; interestingly, this includes a prediction of $300 \mathrm{Zn}^{2+}$ finger transcription factors. ${ }^{48}$ Relevantly, co-addition of gliotoxin and $\mathrm{Zn}^{2+}$ induced key alterations to abundance of proteins involved in secondary metabolism. Proteins from the gliotoxin biosynthetic cluster, GliM and GliH, were uniquely detected in mycelia exposed to gliotoxin, indicating that combinatorial exposure with $\mathrm{Zn}^{2+}$ prevents activation of gliotoxin cluster expression. While GliM and GliH are induced in response to gliotoxin, these proteins are not detected following BmGT exposure. ${ }^{9}$ This may implicate $\mathrm{Zn}^{2+}$ chelation in the activation of the gliotoxin transcription factor Gliz and the induction of cluster expression. O'Keeffe et al. noted gliotoxin exposure suppresses fumagillin cluster expression in A. fumigatus $\Delta g l i .^{14}$ This result was reflected in the current study, however co-exposure to gliotoxin and $\mathrm{Zn}^{2+}$ reversed this effect, leading to unique detection of fumagillin biosynthetic proteins. As with gliotoxin, the fumagillin cluster is also regulated by a $\left(\mathrm{Zn}^{2+}\right)_{2} \mathrm{Cys}_{6}$ transcription factor (FapR/FumR), ${ }^{49,50}$ possibly implicating $\mathrm{Zn}^{2+}$ chelation in cluster repression, since exogenous $\mathrm{Zn}^{2+}$ blocks gliotoxinassociated repression. These proteomic observations are supported by the switch from gliotoxin to fumagillin production in A. fumigatus upon $\mathrm{Zn}^{2+}$ supplementation (Fig. S10, ESI $\dagger$ ).

Incubation of A. fumigatus protein lysates with DTG prior to heat treatment resulted in increased protein aggregation, compared to the solvent control. Oxidoreductases, metal-binding proteins and zinc-binding proteins were significantly enriched amongst these DTG-affected proteins $(p<0.05)$. DTG-induced aggregation of zinc-binding proteins including two alcohol dehydrogenases, AlcC and AFUA_1G04620, and the farnesyltransferase (AFUA_ 4G10330) was observed. This is in line with observed inhibition of mammalian homologs of these proteins by gliotoxin in reducing conditions. ${ }^{16,17}$ AlcC was also observed to increase in abundance in vivo when A. fumigatus $\Delta g l i T$ was treated with a combination of gliotoxin and $\mathrm{Zn}^{2+}$ compared to gliotoxin alone (Table S1, ESI $\dagger$ ), possibly to compensate for loss of activity. AlcC has been identified as the primary hypoxia-responsive ADH in A. fumigatus, with a potential role in pathogenesis ${ }^{51}$ while farnesyltransferase has a role in signalling and also contributes to disease. ${ }^{52}$ Further investigation could elucidate the effect of DTG on the functionality of these proteins in A. fumigatus. Pre-incubation of DTG with excess $\mathrm{Zn}^{2+}$ abrogated this effect, most likely through formation of Zn(DTG) complexes prior to addition to protein lysates, leading to reduced levels of protein aggregation. A number of metallopeptidases (AFUA_6G09190, AFUA_4G07910, AFUA_1G14920 and MepB) were also observed to undergo increased aggregation in response to DTG, while this was prevented in the presence of $\mathrm{Zn}^{2+}$. These peptidases contribute to protein modification and degradation, and so alteration of these processes by DTG has the potential to disrupt protein turnover. Interestingly, gliotoxin has previously been implicated in inhibition of proteolytic activity of human and toxoplasma proteasomes. ${ }^{53,54}$ The cobalamin-independent methionine synthase MetH/D showed a similar response to DTG treatment, with $\mathrm{Zn}^{2+}$ co-addition blocking aggregation. MetH/D contains a zinc-binding site, required for binding and activation of its substrate homocysteine. ${ }^{55}$ DTG-mediated aggregation of MetH/D would interrupt an integral part of primary metabolism and potentially affect pathogenesis. ${ }^{56}$ Interestingly, while metH/D showed no response to gliotoxin in A. fumigatus wild-type, expression was significantly induced in A. fumigatus $\Delta g l i T$ in response to gliotoxin. ${ }^{14}$ Persistence of intracellular DTG, in the 
absence of GliT-mediated oxidation, results in disruption of the methionine cycle, with SAM depletion caused by dysregulation of gliotoxin methylation. ${ }^{8}$ Added to the extensive SAM consumption, DTG-associated destabilisation of methionine synthase through $\mathrm{Zn}^{2+}$-chelation could place an additional strain on the methionine cycle in A. fumigatus $\Delta$ gliT. While further studies are required to confirm if these proteins are directly affected by DTG in vivo, these results present strong targets for future investigations to elucidate the systemic effect of DTG on A. fumigatus. Of course, $\mathrm{Zn}^{2+}$ chelation is likely not the only mechanism by which DTG exerts its effects on the cell, with previous studies illustrating its potential for thiol modification and redox reactions. ${ }^{57,58}$ This methodology also provides an unbiased discovery-based mechanism allowing for the identification of putative targets of DTG in other complex systems.

Interestingly, Müller et al. have shown that allicin (diallyl thiosulphinate) can cause thiol stress and severe growth inhibition in bacteria. ${ }^{59}$ Specifically, Muller et al. revealed that allicin induced protein aggregation, likely due to $S$-allylmercapto protein modification, in crude Escherichia coli cell lysates in a concentrationdependent manner. This is in accordance with our observations of DTG-induced protein aggregation in A. fumigatus protein lysates, although fungal protein destabilisation possibly involves $\mathrm{Zn}^{2+}$ chelation mechanism, as opposed to protein modification. Future work will clarify the relative contribution of either mechanism.

As can be seen in Fig. S8 (ESI $\dagger$ ), gliotoxin addition to A. fumigatus results in uptake, followed by conversion to intracellular DTG and induction/augmentation of gliotoxin biosynthesis, as previously reported in Owens et al. and Dolan et al. ${ }^{8,15}$ Based on our new observations, we now extend this model and provide a mechanistic link between the intracellular presence of DTG and (i) $\mathrm{Zn}^{2+}$ depletion leading to increased $\mathrm{ZrfB}$ abundance, as well as (ii) potential $\mathrm{Zn}^{2+}$ chelation and destabilisation of metalloenzymes. Interestingly, the membrane-permeable zinc chelator, TPEN, which has been used in vivo ${ }^{60}$ and in A. fumigatus studies, ${ }^{61}$ demonstrated lower AP inhibition than DTG (Fig. 3). The dissociation constant $\left(K_{\mathrm{d}}\right)$ of $\mathrm{Zn}(\mathrm{TPEN})$ has been reported as $6.4 \times 10^{-16} \mathrm{M}\left(\mathrm{p} K_{\mathrm{d}} 15.2\right)$ at $\mathrm{pH} 7.4$, with the same $1: 1$ stoichiometry as the $\mathrm{Zn}$ (DTG) complex. ${ }^{62,63}$ Future studies will quantify the affinity of DTG for $\mathrm{Zn}^{2+}$ however, considering DTG caused significantly greater AP inhibition than TPEN, it is reasonable to conclude that DTG is a better $\mathrm{Zn}^{2+}$ chelator than TPEN under the conditions tested. TPEN has been shown to act co-operatively with the antifungal drug caspofungin to significantly improve survival in a mouse model system of Invasive Pulmonary Aspergillosis compared to either caspofungin or TPEN administration alone. ${ }^{64}$ This exciting development is important because exposure to combinations of antifungal drugs, acting in synergy, may address both the development of pathogen resistance and toxicity of high therapeutic levels of either drug alone to the recipient. Although TPEN administration may not have any immediate harmful effects in animals, its safety profile following co-administration with antifungal drugs is unknown. Our observation of DTG as an intracellular $\mathrm{Zn}^{2+}$ chelator, ideally positions it as a potential endogenous anti-fungal, especially if strategies to interfere with its enzymatic elimination are elucidated in future research.

\section{Conclusions}

Overall, new in vivo and in vitro interactions between $\mathrm{Zn}^{2+}$ and DTG, with multiple biological consequences, are revealed. A. fumigatus is a pathogen for which limited therapeutic options exist. Although much recent work has greatly increased the understanding of this and other fungal species, investigation of cryptic interaction between $\mathrm{Zn}^{2+}$ and BGC-encoded metabolite functionality needs urgent study. Any new systems identified could not only represent antifungal drug targets, but also inform on the exploitation of BGC-encoded, dithiol-containing, metabolites to restrict $\mathrm{Zn}^{2+}$ availability in many microbial species.

\section{Conflicts of interest}

There are no conflicts to declare.

\section{Acknowledgements}

AAS was funded by a Government of Ireland Postdoctoral Fellowship from the Irish Research Council (GOIPD/2015/516). SFD was funded by a SPUR studentship from Maynooth University. Mass spectrometry facilities were funded by Science Foundation Ireland (12/RI/2346 (3)) and the Irish Higher Education Authority.

\section{References}

1 J. W. Bok, D. Chung, S. A. Balajee, K. A. Marr, D. Andes, K. F. Nielsen, J. C. Frisvad, K. A. Kirby and N. P. Keller, Infect. Immun., 2006, 74, 6761-6768.

2 R. A. Owens, G. O'Keeffe, K. A. O'Hanlon, L. Gallagher and S. Doyle, in Human Pathogenic Fungi: Molecular Biology and Pathogenic Mechanisms, ed. D. J. Sullivan and G. P. Moran, Caister Academic Press, 2014, pp. 163-194.

3 B. Li, W. J. Wever, C. T. Walsh and A. A. Bowers, Nat. Prod. Rep., 2014, 31, 905-923.

4 S. K. Dolan, G. O'Keeffe, G. W. Jones and S. Doyle, Trends Microbiol., 2015, 23, 419-428.

5 D. H. Scharf, N. Remme, T. Heinekamp, P. Hortschansky, A. A. Brakhage and C. Hertweck, J. Am. Chem. Soc., 2010, 132, 10136-10141.

6 B. Li and C. T. Walsh, Biochemistry, 2011, 50, 4615-4622.

7 M. Schrettl, S. Carberry, K. Kavanagh, H. Haas, G. W. Jones, J. O'Brien, A. Nolan, J. Stephens, O. Fenelon and S. Doyle, PLoS Pathog., 2010, 6, e1000952.

8 R. A. Owens, G. O'Keeffe, E. B. Smith, S. K. Dolan, S. Hammel, K. J. Sheridan, D. A. Fitzpatrick, T. M. Keane, G. W. Jones and S. Doyle, Eukaryotic Cell, 2015, 14, EC.00055.

9 S. K. Dolan, R. A. Owens, G. O'Keeffe, S. Hammel, D. A. Fitzpatrick, G. W. Jones and S. Doyle, Chem. Biol., 2014, 21, 999-1012.

10 B. Li, R. R. Forseth, A. A. Bowers, F. C. Schroeder and C. T. Walsh, ChemBioChem, 2012, 1-7.

11 P. H. Bernardo, N. Brasch, C. L. L. Chai and P. Waring, J. Biol. Chem., 2003, 278, 46549-46555. 
12 S. Carberry, E. Molloy, S. Hammel, G. O'Keeffe, G. W. Jones, K. Kavanagh and S. Doyle, Fungal Genet. Biol., 2012, 49, 302-312.

13 R. A. Cramer, M. P. Gamcsik, R. M. Brooking, L. K. Najvar, W. R. Kirkpatrick, T. F. Patterson, C. J. Balibar, J. R. Graybill, J. R. Perfect, S. N. Abraham and W. J. Steinbach, Eukaryotic Cell, 2006, 5, 972-980.

14 G. O’Keeffe, S. Hammel, R. A. Owens, T. M. Keane, D. A. Fitzpatrick, G. W. Jones and S. Doyle, BMC Genomics, 2014, 15, 894.

15 S. K. Dolan, T. Bock, V. Hering, R. A. Owens, G. W. Jones, W. Blankenfeldt and S. Doyle, Open Biol., 2017, 7, 160292.

16 P. Waring, A. Sjaarda and Q. H. Lin, Biochem. Pharmacol., 1995, 49, 1195-1201.

17 D. M. Vigushin, N. Mirsaidi, G. Brooke, C. Sun, P. Pace, L. Inman, C. J. Moody and R. C. Coombes, Med. Oncol., 2004, 21, 21-30.

18 K. M. Cook, S. T. Hilton, J. Mecinovic, W. B. Motherwell, W. D. Figg and C. J. Schofield, J. Biol. Chem., 2009, 284, 26831-26838.

19 K. M. Reece, E. D. Richardson, K. M. Cook, T. J. Campbell, S. T. Pisle, A. J. Holly, D. J. Venzon, D. J. Liewehr, C. H. Chau, D. K. Price and W. D. Figg, Mol. Cancer, 2014, 13, 91.

20 L. Lauinger, J. Li, A. Shostak, I. A. Cemel, N. Ha, Y. Zhang, P. E. Merkl, S. Obermeyer, N. Stankovic-Valentin, T. Schafmeier, W. J. Wever, A. A. Bowers, K. P. Carter, A. E. Palmer, H. Tschochner, F. Melchior, R. J. Deshaies, M. Brunner and A. Diernfellner, Nat. Chem. Biol., 2017, 13, 709-714.

21 A. Abad, J. V. Fernández-Molina, J. Bikandi, A. Ramírez, J. Margareto, J. Sendino, F. Luis Hernando, J. Pontón, J. Garaizar and A. Rementeria, Rev. Iberoam. Micol., 2010, 27, 155-182.

22 C. Coméra, K. André, J. Laffitte, X. Collet, P. Galtier and I. Maridonneau-Parini, Microbes Infect., 2007, 9, 47-54.

23 J. J. Bennison, R. M. Nottingham, E. L. Key and J. J. Parkins, N. Z. Vet. J., 2010, 58, 201-206.

24 J. C. Woodcock, W. Henderson and C. O. Miles, J. Inorg. Biochem., 2001, 85, 187-199.

25 M. A. Moreno, O. Ibrahim-Granet, R. Vicentefranqueira, J. Amich, P. Ave, F. Leal, J.-P. Latge and J. A. Calera, Mol. Microbiol., 2007, 64, 1182-1197.

26 J. Amich, R. Vicentefranqueira, E. Mellado, A. Ruiz-Carmuega, F. Leal and J. A. Calera, Cell. Microbiol., 2014, 16, 548-564.

27 R. Vicentefranqueira, J. Amich, P. Laskaris, O. IbrahimGranet, J. P. Latge, H. Toledo, F. Leal and J. A. Calera, Front. Microbiol., 2015, 6, 160.

28 S. Yasmin, B. Abt, M. Schrettl, T. A. A. Moussa, E. R. Werner and H. Haas, Fungal Genet. Biol., 2009, 46, 707-713.

29 S. Doyle, G. W. Jones and S. K. Dolan, Fungal Biol., 2018, 122, 214-221.

30 A. N. Chan, A. L. Shiver, W. J. Wever, S. Z. A. Razvi, M. F. Traxler and B. Li, Proc. Natl. Acad. Sci. U. S. A., 2017, 114, 2717-2722.

31 E. B. Smith, S. K. Dolan, D. A. Fitzpatrick, S. Doyle and G. W. Jones, Microb. Cell, 2016, 3, 120-125.
32 N. M. Moloney, R. A. Owens, P. Meleady, M. Henry, S. K. Dolan, E. Mulvihill, M. Clynes and S. Doyle, J. Proteomics, 2016, 136, 99-111.

33 J. Cox, M. Y. Hein, C. A. Luber, I. Paron, N. Nagaraj and M. Mann, Mol. Cell. Proteomics, 2014, 13, 2513-2526.

34 S. Tyanova, T. Temu, P. Sinitcyn, A. Carlson, M. Y. Hein, T. Geiger, M. Mann and J. Cox, Nat. Methods, 2016, 13, 731-740.

35 S. Priebe, C. Kreisel, F. Horn, R. Guthke and J. Linde, Bioinformatics, 2015, 31, 445-446.

36 A. Shevchenko, H. Tomas, J. Havlis, J. V. Olsen and M. Mann, Nat. Protoc., 2007, 1, 2856-2860.

37 L. Manzanares-Miralles, Ö. Sarikaya-Bayram, E. B. Smith, S. K. Dolan, Ö. Bayram, G. W. Jones and S. Doyle, J. Proteomics, 2016, 131, 149-162.

38 L. Gallagher, R. A. Owens, G. O'Keeffe, S. K. Dolan, M. Schrettl, K. Kavanagh, G. Jones and S. Doyle, Eukaryotic Cell, 2012, 11, 1226-1238.

39 J. Amich, R. Vicentefranqueira, F. Leal and J. A. Calera, Eukaryotic Cell, 2010, 9, 424-437.

40 K.-S. Shin, N.-J. Kwon and J.-H. Yu, Curr. Genet., 2009, 55, 631-641. 41 K. A. O’Hanlon, T. Cairns, D. Stack, M. Schrettl, E. M. Bignell, K. Kavanagh, S. M. Miggin, G. O'Keeffe, T. O. Larsen and S. Doyle, Infect. Immun., 2011, 79, 3978-3992.

42 M. F. Mabanglo, M. A. Hast, N. B. Lubock, H. W. Hellinga and L. S. Beese, Protein Sci., 2014, 23, 289-301.

43 H.-W. Park, S. R. Boduluri, J. F. Moomaw, P. J. Casey and L. S. Beese, Science, 1997, 275, 1800-1805.

44 A. Kocyła, A. Pomorski and A. Krezel, J. Inorg. Biochem., 2015, 152, 82-92.

45 C. Davis, N. Gordon, S. Murphy, I. Singh, K. Kavanagh, S. Carberry and S. Doyle, Anal. Bioanal. Chem., 2011, 401, 2519-2529.

46 J. J. Coleman, S. Ghosh, I. Okoli and E. Mylonakis, PLoS One, 2011, 6, e25321.

47 W.-L. Liang, X. Le, H.-J. Li, X.-L. Yang, J.-X. Chen, J. Xu, H.-L. Liu, L.-Y. Wang, K.-T. Wang, K.-C. Hu, D.-P. Yang and W.-J. Lan, Mar. Drugs, 2014, 12, 5657-5676.

48 C. C. Staats, L. Kmetzsch, A. Schrank and M. H. Vainstein, Front. Cell. Infect. Microbiol., 2013, 3, 65.

49 P. Wiemann, C. Guo, J. M. Palmer, R. Sekonyela and C. C. C. Wang, Proc. Natl. Acad. Sci. U. S. A., 2013, 110, 17065-17070.

50 S. Dhingra, A. L. Lind, H. C. Lin, Y. Tang, A. Rokas and A. M. Calvo, PLoS One, 2013, 8, 1-16.

51 N. Grahl, S. Puttikamonkul, J. M. Macdonald, M. P. Gamcsik, L. Y. Ngo, T. M. Hohl and R. A. Cramer, PLoS Pathog., 2011, 7, e1002145.

52 T. S. Norton, Q. Al Abdallah, A. M. Hill, R. V. Lovingood and J. R. Fortwendel, Virulence, 2017, 8, 1401-1416.

53 M. Kroll, F. Arenzana-Seisdedos, F. Bachelerie, D. Thomas, B. Friguet and M. Conconi, Chem. Biol., 1999, 6, 689-698.

54 A. Paugam, C. Creuzet, J. Dupouy-Camet and P. Roisin, Parasitol. Res., 2002, 88, 785-787.

55 R. W. Wheatley, K. K. S. Ng and M. Kapoor, Arch. Biochem. Biophys., 2016, 590, 125-137.

56 J. Amich, M. Dümig, G. O'Keeffe, J. Binder, S. Doyle, A. Beilhack and S. Krappmann, Infect. Immun., 2016, IAI.01124. 
57 R. D. Eichner, P. Waring, A. M. Geue, A. W. Braithwaite and A. Mullbacher, J. Biol. Chem., 1988, 263, 3772-3777.

58 A. M. Hurne, C. L. L. Chai and P. Waring, J. Biol. Chem., 2000, 275, 25202-25206.

59 A. Müller, J. Eller, F. Albrecht, P. Prochnow, K. Kuhlmann, J. E. Bandow, A. J. Slusarenko and L. I. O. Leichert, J. Biol. Chem., 2016, 291, 11477-11490.

60 E. Cho, J.-J. Hwang, S.-H. Han, S. J. Chung, J.-Y. Koh and J.-Y. Lee, Neurotoxic. Res., 2010, 17, 156-166.
61 S. J. Lulloff, B. L. Hahn and P. G. Sohnle, J. Lab. Clin. Med., 2004, 144, 208-214.

62 A. Krężel and W. Maret, Arch. Biochem. Biophys., 2016, 611, 3-19.

63 A. E. Martell and R. M. Smith, Critical Stability Constants, Plenum Press, New York, 1974.

64 P. Laskaris, A. Atrouni, J. A. Calera, C. d'Enfert, H. MunierLehmann, J.-M. Cavaillon, J.-P. Latge and O. IbrahimGranet, Antimicrob. Agents Chemother., 2016, 60, 5631-5639. 